\title{
Innovations in academic evaluation for China's higher education
}

\author{
Zhixiong Li \\ College of Literature and Journalism, Xiangtan University, Xiangtan, Hunan, P. R. China 411105 \\ Email address: \\ 1zxxtu@163.com
}

To cite this article:

Zhixiong Li. Innovations in Academic Evaluation for China's Higher Education. Education Journal. Vol. 3, No. 4, 2014 , pp. $256-260$. doi: $10.11648 /$ j.edu. 20140304.18

\begin{abstract}
In China's higher education, the unfairly formulated ways of evaluation underscore an urgent need for innovations in academic evaluation. The unfair ways, focusing on privileged publications and relying on a few judges, make it difficult for scholars to publish their academic achievements in privileged publications. Thus unpublished ones should be regarded as a part of their academic achievement. Peer reviewers and committee members are the only judges, who cannot guarantee fairness in their evaluation of manuscripts. But those people who expect intellectual benefit from scholars are most likely to be serious in judging the academic value of the scholars' achievements. Therefore college students should be treated as the judges of scholars' academic achievements. It would be a good measure to take against the process of commercialization in China's higher education if we could uncage the issue of academic evaluation from the issue of publication. Also, it would be good for both college students and teachers if we invited college students to take part in academic evaluations.
\end{abstract}

Keywords: Innovations, Academic Evaluation, Higher Education

\section{Introduction}

In China today, tantamount to the dramatic economic growth, the growth of higher education boosts Chinese people's satisfaction that China's higher education has already been accomplished as much as it should be regarded as the credit to a powerful China, noticeably the expansion of college campuses, the increase of college students. Then how can people make judgments on the evaluation of a college or a university, since apparently and physically all colleges or universities have expanded somehow? Traditionally in evaluating education Chinese people focus more on teacher rather than student since the former is hierarchically privileged than the latter. In the Exegesis of the Rituals ( $\mathrm{Li}$ Ji Zheng Yi, 礼记正义), teacher as a professional is incomparably regarded as the most privileged. "The ritual for university should be followed like this, if you are a teacher who is reporting to the emperor, then the emperor must not allow you to face him northward (submit yourself to the emperor) because even the emperor has to pay respect to the teacher at this point." (Ruan, Li Ji Zheng $\mathrm{Yi}, 1980)$ What is at this point? The point is about evaluating the knowledge which the teacher has obtained is much greater than anyone else. Then in evaluating a teacher how can we balance her or his teaching achievement with her or his researching achievement? Unfortunately it is usually the latter overtaken the former since the latter is easier to testify than the former. Hence the so-called academic achievement is crucial to the evaluation of higher education in China. To some extents higher education evaluation is simplified as academic evaluation which is indeed not only itself a problematic issue but also how it is evaluated is quite unfair in China's higher educational system.

Academic evaluation is problematic whenever it can not be testified by people's practices and their lives. As for higher education, it is problematic too when it can not be testified by college students. It is college students rather than college teachers who should be the primary beneficiaries of higher education. Hence an academic evaluation for higher education is problematic if there is no participation by college students. Why is Chinese college students almost neglected to take part in the academic evaluation? Actually it is because of the out-of-date educational idea by which the student has been formulated as the object in the educational activities whiles the teacher as the subject. In this way student is always subject to teacher who always creates knowledge, while he or she always accept knowledge. Thus 
unfortunately, college students are never really encouraged to participate in academic evaluation. We can observe these neglect from the publication about academic evaluation for China's higher education by Chinese scholars. None of them have ever mentioned the participation by the students. However they (the scholars) do have paid much attention to the projects, papers, monographs and patent technologies accomplished by teachers rather than any tasks by the students. $^{2}$ (Gao, Li, Wang, 2011; Huang, 2010; Chen, Xiao, $\mathrm{Su}, \mathrm{Li}, 2009)$.

Furthermore, it is even worse than the neglect of college students that adherence to the unfairly formulated ways of academic evaluation. Namely, they are the focus on privileged publication and the reliance on a few judges. There are thousands of presses and publishing houses in China. Theoretically among them there should be publishing competition which can foster academic growth and thereafter provide basis for academic evaluation. Practically, it is not the publishing market but the vested interest group who authorize them to determine academic evaluation. In China today, one of the most important standards to evaluate social science research is CSSCI (China Social Science Citation Index), for science and technology the standard is CSCD (China Science Citation Database). It is a group of scholars representing higher education authority who decide which journal belong to CSSCI or CSCD. Claiming to select the journals according to the amount of citations, they update the CSSCI or CSCD journals biennially. But actually they have never really updated those journals. If you check the CSSCI 2008-2009, 2010-2011 and 2012-2013 to look at the journals categorized as Foreign Literature or as Chinese Literature, you will find that these journals are almost the same. For the Foreign Literature category, there are always the six journals, for the Chinese Literature category, there are fifteen to sixteen almost the same ones. ${ }^{3}$ (CSSCI, 2008-2009, 2010-2011 and 2012-2013) Since the room for publication in these privileged journals is limited, the journal editors usually ask the authors to pay for this room. It is a common practice in China for publication in these privileged journals. Abreast to these privileged journals, most authorities of those prestige colleges and universities in China only recognize the academic achievements published in CSSCI and CSCD journals. Hence it is the vested interest group rather than the publishing market that decide the academic evaluation for China's higher education.

The vested interest group are people who get great advantage from China's higher education, no matter whoever they are supposed to be, peer reviewers, members of committee, chairs of associations, etc. In a word, they are the few judges who can decide all sorts of academic evaluation, rewards, prizes, funds and honors. It is noticeable that professors in power usually can secure several research projects which are too much for them to accomplish. As a scholar points out, "certain professors in virtue of their academic position or reputation can simultaneously get several research funds, though some of them don't make effort to finish the projects and they have their students finish the projects."4 (Wang, 2003) Here the proper relationship between the teacher and the student has been changed, somehow like the one between the capitalist and the work. Other several scholars conclude, "Some distinguished personnel of scientific research, while using their relationship with higher authorities or enterprises, constantly secure research projects. They have actually become contractors of scientific research projects. And the majority of the young personnel who just become university staff, or of the postgraduates, are in name and in fact the workers for the contractors....Administrative leaders, while using their power or relationships built with the higher authorities, so easily obtain the scientific resources that they themselves can be the evaluators for scientific research and thereafter manipulate the approval of the project proposal, finally cause the inequality and injustice in the distribution of scientific resources." 5 (Mao, Weihua. Li, Shiyong. Zhao, Ming. Jiang, Xinhua, January 2007) Inequality and injustice exist not only in the distribution of scientific resources; also exist in other areas as publication of journals, rewards for achievements. In short, they exist all most everywhere in regard with the purpose of academic evaluation in China's higher education.

\section{Analysis}

We come to realize that privileged publication is an obstacle to the academic evaluation for China's higher education. The cause of privileged publication is the monopoly in academic resources by the vested interest group who have been motivated by their avarice for money. In essence, this avarice for money is the drive for the expansion of capitalism in China today. Any upright people including scholars should be aware of this. As for the privileged publication, scholars should unite together to be against it. Then a new standard should be established that unpublished academic achievements could also be regarded as basis for academic evaluation since there are actually economic difficulties for scholars to publish their achievements. In history, this situation is quite common. Some of important works of Karl Marx was published posthumously because of political or economic reason. For example, one of his masterpieces Economic and Philosophic Manuscripts of 1844 "remained unpublished until 1930s.", (Marx, 1988) When Marx died in 1883, he could not be told his academic achievement as manifested in this work. However, we know now that his communist point of view was actually first expressed in this work where we can trace back Marx's celebrity. Marx's example illustrates that unpublished achievements even during one's lifetime does not mean no achievement. Hence publication is not the final stage for one's academic evaluation.

On the other hand, some scholars have over published their achievements which are not really worth the pennies the readers spent. One of these over publications is the publication commercially motivated for money. An example is the enormously publication of text books for college 
students. According to my survey, there is at least a couple of dozen books titled as "Theory of Literature or Literary Theory文学理论或文学原理” in China's current publication market. All of them share all most the same content and form, but they have been in mass production since there are lots of college students readers. If you surf the Amazon to look for any books titled as Theory of Literature or Literary Theory, you are so lucky to be able to collect them from 30 to 38 available. ${ }^{7}$ (Amazon, 文学理论或文学 原理). As we know, the course named as theory of literature or literary theory has been designed as one of the compulsory courses for language and literature majors in Chinese universities or colleges. Hence there is a regular and constant demand for these sort of text books and therefore either publication houses or authors use this demand as a good chance to make money. The other of these over publication is so called 'a series of academic achievement' publication. This is largely due to an institute or a group of scholars who have secured huge fund or grant from government or organization for a particular research purpose, for example, the research project named as 'Foreign Literature Study in the 20th Century'. In order to meet the final evaluation for this research, they have to hurry up to publish several volumes labeled as 'A Series of Foreign Literature Study in the 20th Century 20 世纪外国文学系列 丛书, Again we can search on Amazon or Dangdang which is another prevailing website in China for book sale, we can find plenty of them for sale. My most recent check was on 27 September 2013 and the result was accordingly 17 and $13 .^{8}$ (Amazon, Dangdang, Foreign Literature Study in the 20th Century) Overall, these two forms of over publication share one thing in common: the chiché, whether they are for making or spending money. So what is their use for the college students? What is their use for China's higher education? We have recognized that they are chiché indeed based on the comparison for the study on novel in the four textbooks titled as Theory of Literature or Literary Theory. Please see the table below.

Table 1. Academic Behavior Self-Efficacy Scale Items, Grouped by Factor.

\begin{tabular}{|c|c|c|c|}
\hline name of the textbook & space for the study on novel & topics on novel & novelty on novel \\
\hline $\begin{array}{l}\text { Wenxue Lilun Daoyin } \\
\text { 文学理论导引 }\end{array}$ & 4 pages & $\begin{array}{l}\text { plot and novel } \\
\text { character and novel } \\
\text { category of novel }\end{array}$ & none \\
\hline $\begin{array}{l}\text { Wenxue Lilun Daoyin } \\
\text { 文学理论导引 }\end{array}$ & 11 pages & $\begin{array}{l}\text { narrative and novel } \\
\text { character and novel } \\
\text { narrative theory }\end{array}$ & a few \\
\hline $\begin{array}{l}\text { Wenxue Yuanli } \\
\text { 文学原理 }\end{array}$ & 2 pages & category of novel & none \\
\hline Wenxue Lilun & & character and novel & \\
\hline $\begin{array}{l}\text { Jiaocheng } \\
\text { 文学理论教程 }\end{array}$ & 2 pages & $\begin{array}{l}\text { plot and novel } \\
\text { environment and novel }\end{array}$ & none \\
\hline
\end{tabular}

${ }^{9}(\mathrm{Ji}, 2009),{ }^{10}$ (Wang \& Sun, 2005), ${ }^{11}$ (Wang, 2002), ${ }^{12}$ (Tong, 1998)

These four textbooks about Theory of Literature or Literary Theory is only a minor among those a couple of dozen I mentioned before. However they are typical examples to tell the market motivation for China's higher education. Noticeably, it is useless to republish them. But the university locations of the editors of the textbooks have indicated the market divisions in China for book sale aimed at college students. Actually all the editors are renowned professors at these universities where they have been taught students Theory of Literature or Literary Theory. We can observe: Ji-Xiangtan University-Southern China, Wang \& Sun-Central China Normal University-Central China, Wang-Zhejiang University-Eastern China; and Tong-Beijing Normal University-Northern China. Annually, there is about 300 literature majors who have to use these sort of textbooks because Theory of Literature or Literary Theory is designed as one of their compulsory courses. Hence we can see the potential for book sale. Then it is not surprising why the similar textbooks co-exist in the book sale market. Of course, this market orientation is not strictly to the benefit of the college student If it was, there would be somehow academic novelty.

Why is the college student rather than the teacher who should be the primary beneficiary in China's higher education? As for any forms or levels of education, the primary purpose is to benefit the student rather than the teacher. The father of Chinese education Confucius (551-479 BC) once said, "instruction knows no class distinction."13 (Ruan, Lun Yu Zhu Shu 论语注疏, 1980) What Confucius tells us is the purpose of education. Instruction was the primary educational activity not only during Confucius era but also in later generations prior to the late 19th or early 20th century when Chinese modern education emerged. In other words, we should not deprive of anyone's right of education. Hence people who are instructed in educational activities should be the primary beneficiaries of education. And this is no doubt the purpose of education. Therefore the role of teacher is to provide student with educational service. Han Yu 韩愈(768-824 AD), a great literati, thinker and politician in Tang Dynasty (618-907 AD), concluded in his famous article On Teacher Shi Shuo 师说 that “propagation of the Confucian doctrines, instruction of the Confucian classics, answering questions of the doctrines and the classics are the roles of a teacher."14 (Han, 1980) Thus, ideologically, epistemologically or pedagogically, Han Yu had defined specifically the roles of a teacher. That is to say, the function a teacher performs is to serve the purpose of the student(s). Hence the student's participation should be regarded as a crucial factor in the educational activities. The role of the student is more 
important than that of the teacher in any educational activities, including in the academic evaluation.

Academic research or evaluations are two of the educational activities for higher education. They are two sides of the same coin of academic activity. It is in these two activities that we can carry out the mission of a university. "A university is the source of new knowledge and the place for getting rid of the stale and bringing forth the fresh. Its purpose is to constantly explore and pursue the truth." 15 (Xie, 2006) No doubt, in the exploration and pursuit of the truth, college students especially the postgraduates are the potential and hopeful forces since they are young and promising. Some scholars have clearly stated, "[postgraduates] constitute a promising force for research at colleges and universities. Students' participation have enabled them to acquire basic knowledge and skills by doing research, which is of necessity for their future academic growth."16 (Yang, 1988) obviously, we have treated college students as participants in academic research. Then why should not we treat them as judges in academic evaluation? In other words, should college students be treated as the judges of the scholars' acadmic achievements for China's higher education? The answer is "YES".

Firstly, college students may have realized or will realize that it is themselves rather than their teachers who should be the beneficiaries of higher education, simply they have paid their tuition or other cost of their education. In this sense, they may really be more serious than their teachers while they are evaluating the academic achievements. The purpose of doing evaluation is for their own sake of pursuit of knowledge or truth. They actually know what they really need. They really know what they should learn. Instead, their teachers are not so motivated that they may do the evaluation for sake of interests other than that of the students. Hence it is not surprising that the college students may be more serious than their teachers while for academic evaluation. Secondly, college students are not involved very much in the Guanxi 关系(relationship) which is ingrained in Chinese culture. It is difficult for Peer reviewers or members of committee to avoid these sorts of Guanxi by which they are bound. We can imagine that the college students are so enormous that the evaluatees can not easily establish the Guanxi with them. So I strongly suggest that at least 100 students evaluators should be anonymously selected from database for every academic evaluation. In this way, fair judgments can be made for academic evaluation. Thirdly, the college students do not poison their minds so much with prejudices or ideas as the peer reviewers or council members do. They take open-minded approach to academic innovation, whereas their teachers may be ideologically, culturally, religiously or racially prejudiced. Generally speaking, the professionals are more affected by politics, culture, religion or race than the non-professionals like the students who are not so entrapped in these social affairs. Hence college students are more reliable than those professionals as for the academic evaluation. The academic evaluation should act as a stimulus to China's higher education. If we put the college students as the judges of the academic evaluation, we will see the hope of China's higher education.

\section{Author}

Li Zhixiong is Doctor of Literature, Associate Professor for Comparative Literature and Supervisor for Postgraduate Students at the College of Literature and Journalism, Xiangtan University, Hunan Province, P. R. China. He is also a council member of China Marxist-Leninist Literary Theory Association and of Hunan Association for Comparative \& World Literature Study. He is the author of the book Aristotle's Classical Narrative Theory, Xiangtan University Press 2009, and co-author of the article Hope: The Convergence and Divergence of Marxism and Liberation Theology, Theology Today, 70(2) July, 2013, and author of the article Marxism and Christianity in China for a Harmonious Society, Interreligious Insight, 11(1), July 2013. From February 2012 to January 2013, he was an academic visiting scholar at the Faculty of Theology and Religion, University of Oxford.

\section{References}

[1] Ruan, Yuan. (Ed.). (1980). Li Ji Zheng Yi (The Exegesis of the Rituals) In Shi San Jing Zhu Shu (The Notes and Commentaries of the Thirteen Classics) Volume $(\Pi)$. Beijing: Zhonghua Shuju (China Bookstore Press), p. 1523.

[2] Gao Hongli, Li Xueqian \& Wangqian. The Evaluation Index and Empirical Study of Scientific Research in Universities and Colleges 高校科研评估指标及其实证研究. Education Science, April 2011, Volume 27, Number 2, pp. 71-5. Liu Huiqing. An Index System Design for Academic Evaluation in Provincial Level Universities 地方高校科研评估指标系 统设计. Science \& Technology Assessment, Number 8, 2010 Chen Ling, Xiao Hui, SU Jie \& Li Lin. Establishing Research Evaluation Indictors System to Improve Discipline Construction and Development 建立科研评估指示体系, 促进学科建设与发展. Chinese Hospital, May 2009, Volume 13, Number 5, pp. 66-8.

[3] CSSCI 2008-2009, 2010-2011 and 2012-2013, please check the following websites respectively:

http://cssci.nju.edu.cn/manage/webedit/uploadfile/2012.4.24 14.34.34_xum1 tnw4.pdf

http://cssci.nju.edu.cn/manage/webedit/uploadfile/2012.4.26 17.43.18_2yq5yr29.pdf

$\overline{\mathrm{h}} \mathrm{ttp} / /$ cssci.nju.edu.cn/manage/webedit/uploadfile/2012.3.26 _15.23.2_c91f92cj.pdf

[4] Wang, Chuhui (Ed.). (2003). Self-Reflection and Construction China's Higher Education in Transformation. Hehui: Hehui University of Industry Press, pp.279-289.

[5] Mao, Weihua. Li, Shiyong. Zhao, Ming. Jiang, Xinhua. On the Tendency and Strategy of the Utilitarian Activities for the Scientific Research in China's Higher Education. (2007). Science \& Technology Progress and Policy, Volume 24 Number 1, pp. 172-173. 
[6] Marx, Karl. (1988). Economic and Philosophic Manuscripts of 1844 and the Communist Manifesto, Martin Milligan (trans.), New York: Prometheus Books, p. 5.

[7] Amazon, 文学理论或文学原理, please check the website: http://www.amazon.cn/

[8] To examine the published amount of "Foreign Literature Study in the 20th Century 20 世纪外国文学” in current Chinese bookmarkets, please check, http://www.amazon.cn/ and http://search.dangdang.com

[9] Ji, Shuihe.(Ed.). (2009). Wenxue Lilun Daoyin. Xiangtan: Xiangtan University Press, 1st edn, pp. 127-30.

[10] Wang, Xianpei \& Sun, Wenxian.(Ed.). (2005). Wenxue Lilun Daoyin. Beijing: Higher Education Press, 1st edn, pp. 79-89.

[11] Wang, Yuanxiang.(Ed.). (2002). Wenxue Yuanli. Guilin: Guangxi Normal University Press, 1st edn, pp. 127-30.

[12] Tong, Qingbing.(Ed.). (1998). Wenxue Lilun Jiaocheng. Beijing: higher Education Press, 2nd edn, pp. 171-2.
[13] Ruan, Yuan. (Ed.). (1980). Lun Yu Zhu Shu (The Notes and Commentaries of the Analects) In Shi San Jing Zhu Shu(The Notes and Commentaries of the Thirteen Classics) Volume(П). Beijing: Zhonghua Shuju ( China Bookstore Press ), p. 2518.

[14] Han, Yu. (1980). Zhongguo Lidai Wenxue Zuopin Xuandu (Selected Works of Literatue in the Successive Dynasties in China), Volume 1, Compilation 2. Zhu, Dongrun. (Ed.). Shanghai: Shanghai Guji Chubanshe (Shanghai Ancient Books Press), p. 298.

[15] Xie, Anbang. (Ed.). (2006). The New Progress of China's Higher Education · 2004. Shanghai: Eastern China Normal University Press, p. 17.

[16] Yang, Zhiling. Lin, Bing. \& Su, Weichang. (1988). Higher Education in the People's Republic of China. Beijing: Beijing Normal University Press, p. 185. 